\title{
ClubMed? Cyclical fluctuations in the Mediterranean basin*
}

\author{
Fabio Canova ${ }^{\dagger}$ \\ ICREA-UPF, CREI, CREMeD, BSGE and CEPR \\ Matteo Ciccarelli ${ }^{\ddagger}$ \\ European Central Bank
}

March 2012

\begin{abstract}
We investigate macroeconomic fluctuations in the Mediterranean their similarities and convergence. A model with four indicators, roughly covering the West, the East and the Middle East and the North Africa portions of the Mediterranean, characterizes well the historical experience since the early 1980. Idiosyncratic causes still dominate domestic cyclical fluctuations in many countries. Convergence and divergence coexist are local and transitory. The cyclical outlook for the next few years is rosier for the East than for the West.
\end{abstract}

JEL classification: C11; C33; E32.

Key words: Bayesian Methods; Business cycles; Mediterranean basin; Developing and developed countries.

${ }^{*}$ We thank Giancarlo Corsetti (the editor), two anonymous referee, L. Stracca, T. Poghosyan, O. Karagedikli and the participants of the conferences 'International Business Cycle Linkages', Budapest; 'The international transmission of international shocks to open economies', Wellington; of the Eurostat 6th Colloquium on Modern Tools for Business Cycle Analysis, Luxemburg, of the Second EuroMediterranean workshop, Barcelona, and of seminars at the Bank of France and the University of Amsterdam for comments and suggestion. Canova acknowledges the financial support of the Spanish Ministry of Science and Technology through the grant ECO2009-08556, of the Barcelona Graduate School of Economics and of the CREMeD.

${ }^{\dagger}$ Address: Universitat Pompeu Fabra, Ramon Trias Fargas 25-27, 08005 Barcelona, Spain. Email: fabio.canova@upf.edu.

${ }^{\ddagger}$ Corresponding author: Kaiserstrasse 29, 60311 Frankfurt am Main, Germany. Email: Matteo.Ciccarelli@ecb.europa.eu. 


\section{Introduction}

The nature and the transmission properties of business cycles have dramatically changed since the early 1980s. On the one hand, emerging market economies now play an important role in shaping world business cycles, previously determined by a handful of developed countries. On the other, trade and financial linkages have increased, making international spillovers potentially much more relevant than in the past. While Latin America and Asia are leading examples of these new tendencies and the evolution of their business cycles features has been extensively documented in the literature (see Kose and Prasad (2010) for a recent account), much less is known about the cyclical fluctuations in other areas, and whether their time variations conform to these international tendencies. This paper partially fills the gap providing evidence on the features and the evolution of business cycles in 16 Mediterranean countries and on the extent of interdependencies present in the area.

Why focusing attention on the Mediterranean? At least two reasons come to mind. First, the basin is a miniature world economy, in the sense that developed, emerging and frontier economies are well represented. Moreover, countries are in close regional proximity and share a number of cultural, identity and historical traits. Thus, the area offers an ideal laboratory to also study the connection between business cycles and the level of development and to better understand the role that national idiosyncrasies have in shaping business cycles and the international transmission of cyclical shocks. The literature has extensively debated the topic but no consensus has been reached. For example, Kydland and Zarazaga (2002), Aguiar and Gopinath (2008), among others, have argued that business cycles in developed and developing countries are alike and that differences in the productivity process are sufficient to account for existing cyclical differences. Chang and Fernandez (2010), Benczur and Raftai (2010), and Garcia-Cicco et al. (2011), instead suggest that heterogeneities are pervasive and that cyclical differences in the two groups of countries have to do more with the structure of the economies than with the productivity process. 
Second, the Union for the Mediterranean (UFM) partnership (see www.eeas.europa.eu /euromed/ index_en.htm), which started with the Barcelona process in 1995, seeks the establishment of free trade agreements in the area, wants to promote regional interdependences, and intends to share the prosperity the new order generates. The conventional wisdom suggests that increased cross-border interdependences should lead to convergence of business cycle fluctuations. Greater openness to trade and increased financial and migration flows should, in fact, make economies more sensitive to external shocks and increase the comovements of domestic and foreign variables by expanding or intensifying the channels through which shocks spill across countries. An alternative view indicates that increased economic integration could lead to more asynchronous output fluctuations, as countries specialize in the production of goods for which they have comparative advantage, and freely trade them in the world markets. Thus, production cycles could become completely idiosyncratic while consumption cycles are perfectly correlated (see e.g. Heathcothe and Perri, 2004). Helbling and Bayoumi (2003), Kose et al. (2009), Walti (2009), Altug and Bildirici (2010) among others, have studied whether world business cycles are converging or not, but the evidence they produced is somewhat contradictory. Nevertheless, investigators studying the phenomena have noticed that world business cycles have changed following the financial crisis of 2008 and that many countries escaped or quickly recovered from the recession that hit the developed world. This seems to be true also for parts of the Mediterranean (see Sturm and Sauter, 2010) and the turmoil appears to have been minor relative, e.g. Central and Eastern Europe. Thus, are business cycles in the Mediterranean basin becoming more similar? Have increased interdependences brought about cyclical convergence? What is the expected evolution of Mediterranean cycles in the years to come in light of the policies pursued by the EU?

To analyze these issues the paper employs a panel VAR model of the type developed in Canova and Ciccarelli (2009), and Canova et al. (2007). The setup can handle large dynamic panels displaying country specific dynamics and cross country lagged interdependencies; it allows for time variations in the correlation structure 
across variables and countries; and it facilitates the construction of observable indicators capturing regional, national or exogenous influences. Finally, it is well suited to study the international transmission of shocks from one country or area to another.

We uncover three main facts. Cyclical fluctuations in the Mediterranean are heterogeneous. On the one hand, regional factors are important and the dynamics of the regional indicators differ in terms of volatility, persistence and synchronicity. Interestingly, trade openness, the level of development, or the monetary arrangement a country chooses do not determine the composition of a "region"; instead, geographical proximity matters. On the other, the relative importance of regional factors for domestic fluctuations is far from uniform and idiosyncratic influences dominate the dynamics of macroeconomic variables in several countries. Hence, Mediterranean fluctuations are quite different from those observed in other regions of the world.

Second, increased regional interdependences have not changed much these features and, if we exclude the recent recession, there is little evidence that the relative importance of idiosyncratic factors declines over time. Furthermore, since time variations after 1995 are negligible, it seems that EU policies have not done much to reduce the segmented nature of Mediterranean business cycles.

Third, time variations in the structure of regional cycles are not easily reconciled with either a pure convergence or a pure decoupling view: both phenomena are in fact present but, more importantly, both are local and temporary. Moreover, absent some major structural change, global convergence is unlikely to take place and even regional convergence seems to be difficult to achieve in the years to come: GDP growth will be persistently below its national average in the major EU countries, while countries in the east side of the Mediterranean will return to above average growth rates. For the rest of the countries, GDP growth will settle at the historical mean level.

The rest of paper is organized as follows. The next section describes the empirical model and section 3 the data. Section 4 presents the results, section 5 reports some robustness checks and section 6 concludes. 


\section{The empirical model}

The empirical model employed in the analysis has the form:

$$
y_{i t}=D_{i t}(L) Y_{t-1}+F_{i t}(L) W_{i t}+e_{i t}
$$

where $i=1, \ldots, N$ indicates countries, $t=1, \ldots, T$ time, and $L$ the lag operator; $y_{i t}$ is a $G \times 1$ vector for each $i$ and $Y_{t}=\left(y_{1 t}^{\prime}, \ldots y_{N t}^{\prime}\right)^{\prime} ; D_{i t, j}$ are $G \times N G$ matrices for each lag $j=1, \ldots, p, F_{i t, j}$ are $G \times M$ matrices each lag $j=1, \ldots, q ; W_{i t}$ is a $M \times 1$ vector of exogenous variables, $e_{i t}$ a $G \times 1$ vector of disturbances with variance $\Sigma_{i}$.

Model (1) displays three important features, which makes it ideal for our study. First, dynamic relationships are allowed to be country specific. Without such a feature, similarities could not be evaluated, heterogeneity biases may be present, and economic conclusions easily distorted. Second, whenever the $N G \times N G$ matrix $D_{t}(L)=\left[D_{1 t}(L), \ldots, D_{N t}(L)\right]^{\prime}$, is not block diagonal for some $L$, cross-unit lagged interdependencies matter. Thus, dynamic feedback across countries are possible and this greatly expands the type of interactions our empirical model can account for. Third, the coefficients are allowed to vary over time. Absent time variations, it would be difficult to study convergence and to examine the evolution of business cycles characteristics. These features add realism to the empirical model and avoid important specification errors (see Canova and Ciccarelli, 2009, for a discussion), but they have a cost. To see why, rewrite (1) in regression format as:

$$
Y_{t}=Z_{t} \delta_{t}+E_{t} \quad E_{t} \sim N(0, \Omega)
$$

where $Z_{t}=I_{N G} \otimes X_{t}^{\prime} ; \quad X_{t}^{\prime}=\left(Y_{t-1}^{\prime}, \quad Y_{t-2}^{\prime}, \ldots, Y_{t-p}^{\prime}, W_{t}^{\prime}, W_{t-1}^{\prime}, \ldots, W_{t-q}^{\prime}\right), \quad \delta_{t}=$ $\left(\delta_{1 t}^{\prime}, \ldots, \delta_{N t}^{\prime}\right)^{\prime}$ and $\delta_{i t}$ are $G k \times 1$ vectors containing, stacked, the $G$ rows of the matrix $D_{i t}$ and $F_{i t}$, while $Y_{t}$ and $E_{t}$ are $N G \times 1$ vectors of endogenous variables and of random disturbances. Since $\delta_{t}$ varies in different time periods for each country-variable pair, it is impossible to estimate it using unrestricted classical methods. However, even if $\delta_{t}=\delta, \forall t$, its sheer dimensionality (there are $k=N G p+M q$ parameters in each equation) prevents any meaningful unconstrained estimation. 


\subsection{The factorization of the coefficient vector $\delta_{t}$}

To circumvent this problem, we estimate a lower dimensional vector $\theta_{t}$, which is assumed to determine $\delta_{t}$. Let

$$
\delta_{t}=\Xi \theta_{t}+u_{t} \quad u_{t} \sim N(0, \Sigma \otimes V)
$$

where $\Xi$ is a matrix of zeros and ones, $\operatorname{dim}\left(\theta_{t}\right)<<\operatorname{dim}\left(\delta_{t}\right)$, and $u_{t}$ is a vector of disturbances, capturing unmodelled features in the coefficient vector $\delta_{t}$. For example, in the specifications we consider $\Xi \theta_{t}=\Xi_{1} \theta_{1 t}+\Xi_{2} \theta_{2 t}+\Xi_{3} \theta_{3 t}$ where $\Xi_{1}, \Xi_{2}, \Xi_{3}$ are loading matrices of dimensions $N G k \times s, N G k \times N, N G k \times G$, respectively; $\theta_{1 t}, \theta_{2 t}, \theta_{3 t}$ are mutually orthogonal factors capturing, respectively, movements in the coefficient vector which are common across $s$ groups of countries and variables; movements which are country specific; and movements which are variable specific.

Factoring $\delta_{t}$ as in (3) is advantageous in many respects. Computationally, it reduces the problem of estimating $N G k$ coefficients into the one of estimating $s+N+G$ factors characterizing their dynamics. Practically, the factorization (3) transforms an overparametrized panel VAR into a parsimonious SUR model, where the regressors are averages of certain right-hand side VAR variables. To see this, substitute (3) into (2) to have

$$
Y_{t}=\mathcal{Z}_{t} \theta_{t}+v_{t}
$$

where $\mathcal{Z}_{t}=Z_{t} \Xi$ and $v_{t}=E_{t}+Z_{t} u_{t}$. Economically, the specification in (3) is convenient since it allows us to decompose fluctuations in $Y_{t}$, and measure the relative importance, e.g., of common vs. country specific or of predetermined vs. exogenous influences, and study their time evolution. For example, when $\theta_{t}$ has at least two dimensions, $W L I_{t}=\mathcal{Z}_{1 t} \theta_{1 t}$ is a common indicator for $Y_{t}$, while $C L I_{t}=\mathcal{Z}_{2 t} \theta_{2 t}$ is a vector of country specific indicators. Furthermore, since $Z_{t}$ includes predetermined and exogenous variables, each indicator can be decomposed into its predetermined and its exogenous components, i.e. $W L I_{t}=W L I_{t}^{e x}+W L I_{t}^{p r e}$, where $W L I_{t}^{e x}=\mathcal{Z}_{1 t}^{e x} \theta_{1 t}, W L I_{t}^{\text {pre }}=\mathcal{Z}_{1 t}^{\text {pre }} \theta_{1 t} . W L I_{t}$ and $C L I_{t}$ are correlated since the same variables enter in $\mathcal{Z}_{1 t}$ and $\mathcal{Z}_{2 t}$, but become uncorrelated as $\mathrm{N}$ increases. 
To complete the specification we need to describe the evolution of $\theta_{t}$ over time and the features of its time zero distribution. We let

$$
\theta_{t}=\theta_{t-1}+\eta_{t} \quad \eta_{t} \sim N\left(0, B_{t}\right)
$$

with $B_{t}=\gamma_{1} * B_{t-1}+\gamma_{2} * \bar{B}$, where $\gamma_{1}, \gamma_{2}$ are scalars, and $\bar{B}$ is block diagonal. We set $\Sigma=\Omega, V=\sigma^{2} I_{k}$; and let $E_{t}, u_{t}$ and $\eta_{t}$ be mutually independent.

In (5) the factors evolve over time as random walks; we choose this specification, after experimenting with various candidate law of motions since it is parsimonious and allows to fit the data very well. The spherical assumption on $V$ reflects the fact that the factors have similar units, while setting $\Sigma=\Omega$ is standard (see e.g. Kadiyala and Karlsson, 1997). The variance of $\eta_{t}$ is allowed to be time varying (following Canova, 1993) to account for generic volatility clustering in $Y_{t}$. Time invariant structures $\left(\gamma_{1}=\gamma_{2}=0\right)$, and homoschedastic variances $\left(\gamma_{1}=0\right.$ and $\left.\gamma_{2}=1\right)$ are special cases of the assumed process. The block diagonality of $\bar{B}$ guarantees orthogonality of the factors, which is preserved a-posteriori, and hence their identifiability. Finally, independence among the errors is standard.

To summarize, our estimable empirical model has the state space structure:

$$
\begin{aligned}
Y_{t} & =\left(Z_{t} \Xi\right) \theta_{t}+v_{t} \\
\theta_{t} & =\theta_{t-1}+\eta_{t}
\end{aligned}
$$

The structure of (6)-(7) differs from the one commonly used in the time varying coefficient literature - typically, the variance of $v_{t}$, rather than the variance of $\eta_{t}$, is time varying. However, in a reduced form sense, the two specifications are equivalent. Thus, our specification can also capture volatility changes in the endogenous variables and has two advantages over alternative setups: it allows for time variations in the shocks of the loadings and in the reduced form errors to be correlated (as it is done, e. g., in ARCH-Models); computationally, it is far less burdensome.

While the model (6)-(7) can be estimated both with classical and Bayesian methods, the latter approach is preferable since the exact small sample distribution of the 
objects of interest can be obtained, even with small $T$ and $N$ (see Del Negro and Schorfheide, forthcoming, for a hierarchical interpretation of this structure).

\subsection{Prior information}

To compute posterior distributions for the parameters in (6)-(7), we assume prior densities for $\phi_{0}=\left(\Omega^{-1}, \bar{B}, \theta_{0}\right)$ and let $\sigma^{2}, \gamma_{1}, \gamma_{2}$ be known. We set $\bar{B}_{i}=b_{i} * I, i=$ $1, \ldots, r$, where $b_{i}$ controls the tightness of factor $i$ in the coefficient vector, and make $p\left(\Omega^{-1}, b_{i}, \theta_{0}\right)=p\left(\Omega^{-1}\right) \prod_{i} p\left(b_{i}\right) p\left(\theta_{0}\right)$ with $p\left(\Omega^{-1}\right)=W\left(z_{1}, Q_{1}\right), \quad p\left(b_{i}\right)=I G\left(\frac{\varpi_{0}}{2}, \frac{S_{0}}{2}\right)$ and $p\left(\theta_{0} \mid \mathcal{F}_{-1}\right)=N\left(\bar{\theta}_{0}, \overline{\mathrm{R}}_{0}\right)$ where $N$ stands for Normal, $W$ for Wishart and $I G$ for Inverse Gamma distributions, and $\mathcal{F}_{-1}$ is the time -1 information set. The prior for $\theta_{0}$ and $(7)$,imply that $p\left(\theta_{t} \mid \mathcal{F}_{t-1}\right)=N\left(\bar{\theta}_{t-1 \mid t-1}, \overline{\mathrm{R}}_{t-1 \mid t-1}+B_{t}\right)$.

Let $\mu=\left(\sigma^{2}, \gamma_{1}, \gamma_{2}, z_{1}, Q_{1}, \varpi_{0}, S_{0}, \bar{\theta}_{0}, \overline{\mathrm{R}}_{0}\right)$. Values for the elements of $\mu$ are either obtained from the data (this is the case for $\bar{\theta}_{0}, Q_{1}$ ) to tune up the prior to the specific application, a-priori selected to produce relatively loose priors (the case of $z_{1}, \varpi_{0}, S_{0}, \overline{\mathrm{R}}_{0}$ ) or chosen to maximize the explanatory power of the model (the case of $\left.\sigma^{2}, \gamma_{0}, \gamma_{1}\right)$ in an empirical Bayes fashion. The values used are: $\gamma_{1}=1.0, \gamma_{2}=0, z_{1}=$ $N \cdot G+5, Q_{1}=\hat{Q}_{1}, \varpi_{0}=S_{0}=1.0, \bar{\theta}_{0}=\hat{\theta}_{0}$ and $\overline{\mathrm{R}}_{0}=\mathrm{I}_{r}$. Here $\hat{Q}_{1}=\operatorname{diag}\left(Q_{11}, \ldots, Q_{1 N}\right)$ and $Q_{1 i}$ is the estimated covariance matrix of the time invariant version for each country VAR; $\hat{\theta}_{0}$ is obtained with OLS on a time invariant version of (1) over the entire sample, and $r$ is the dimension of $\theta_{t}$. Since the in-sample fit improves if $\sigma^{2} \rightarrow 0$, an exact factorization of $\delta_{t}$ is used.

\subsection{Posterior distributions}

To calculate the posterior distribution for $\phi=\left(\Omega^{-1}, b_{i},\left\{\theta_{t}\right\}_{t=1}^{T}\right)$, we combine the prior with the likelihood of the data, which is proportional to

$$
L \propto|\Omega|^{-T / 2} \exp \left[-\frac{1}{2} \sum_{t}\left(Y_{t}-Z_{t} \Xi \theta_{t}\right)^{\prime} \Omega^{-1}\left(Y_{t}-Z_{t} \Xi \theta_{t}\right)\right]
$$

where $Y^{T}=\left(Y_{1}, \ldots, Y_{T}\right)$ denotes the available sample. Using Bayes rule, $p\left(\phi \mid Y^{T}\right)=$ $\frac{p(\phi) L\left(Y^{T} \mid \phi\right)}{p\left(Y^{T}\right)} \propto p(\phi) L\left(Y^{T} \mid \phi\right)$. Given $p\left(\phi \mid Y^{T}\right)$, the posterior distribution for the el- 
ements of $\phi$, can be obtained by integrating out nuisance parameters from $p\left(\phi \mid Y^{T}\right)$. Once these distributions are found, location and dispersion measures for $\phi$ and for any interesting continuous functions of them can be obtained.

For the model we use, it is impossible to compute $p\left(\phi \mid Y^{T}\right)$ analytically. A Monte Carlo techniques which is useful in our context is the Gibbs sampler, since it only requires knowledge of the conditional posterior distribution of $\phi$. Denoting $\phi_{-\kappa}$ the vector $\phi$ excluding the parameter $\kappa$, these conditional distributions are

$$
\begin{aligned}
\theta_{t} \mid Y^{T}, \phi_{-\theta_{t}} & \sim N\left(\bar{\theta}_{t \mid T}, \overline{\mathrm{R}}_{t \mid T}\right) \quad t \leq T, \\
\Omega^{-1} \mid Y^{T}, \phi_{-\Omega} & \sim W i\left(z_{1}+T,\left[, \sum_{t}\left(Y_{t}-Z_{t} \Xi \theta_{t}\right)\left(Y_{t}-Z_{t} \Xi \theta_{t}\right)^{\prime}+Q_{1}^{-1}\right]^{-1}\right) \\
b_{i} \mid Y^{T}, \phi_{-b_{i}} & \sim I G\left(\frac{\varpi^{i}}{2}, \frac{\sum_{t}\left(\theta_{t}^{i}-\theta_{t-1}^{i}\right)^{\prime}\left(\theta_{t}^{i}-\theta_{t-1}^{i}\right)+S_{0}}{2}\right)
\end{aligned}
$$

where $\bar{\theta}_{t \mid T}$ and $\overline{\mathrm{R}}_{t \mid T}$ are the smoothed one-period-ahead forecasts of $\theta_{t}$ and of the variance-covariance matrix of the forecast error, calculated as in Chib and Greenberg (1995), $\varpi^{i}=K+\varpi_{0}$, and $K=T$, if $i=1, K=T g$, if $i=2, K=T N$, if $i=3$, etc.

Under regularity conditions (see Geweke, 2000), cycling through the conditional distributions in (9) produces in the limit draws from the joint posterior. From these, the marginal distributions of $\theta_{t}$ can be computed averaging over draws in the nuisance dimensions. We have performed standard convergence checks: increasing the length of the chain; splitting the chains in pieces after a burn-in period and calculating whether the mean and the variances are similar; checking if cumulative means settle to some value. The results we present are based on chains with 400000 draws: 2000 blocks of 200 draws were made and the last draw for each block is retained. Hence, 2000 draws are used for posterior inference at each $t$.

Once the posterior distribution of $\theta_{t}$ is available one can construct the posterior distribution of the indicators $\mathcal{Z}_{j t} \theta_{j t}$ and of their components. For example, a credible $90 \%$ interval for the common indicator is obtained ordering the $h=1, \ldots, H$ draws of $W L I_{t}^{h}$ for each $t$ and taking the 5 th and the 95 th percentile. In addition, with 
(6)-(7), we can compute the fraction of the fluctuations in $Y_{t}$ due to each indicator, the responses of the indicators to particular shocks and predictive densities for future $Y_{t+i}$. Given the nature of our model, impulse responses are computed as the difference between two conditional expectations, one generated assuming that a subset of the $v_{t}$ is equal to one at $\mathrm{t}$ and zero afterwards and one generated assuming that $v_{t}$ is zero at all $\mathrm{t}$ - for details see Canova and Ciccarelli (2009). Responses of the indicators are obtained calculating first the responses of the variables and appropriately averaging them across variables and countries.

\section{The data}

The data comes from the World Economic Outlook (WEO) database of the International Monetary Fund (IMF) released in the Spring 2011, and covers 16 countries from 1980 to 2010: Portugal, Spain, France, Italy, Greece, Albania, Cyprus, Malta, Turkey, Israel, Jordan, Syria, Egypt, Tunisia, Algeria and Morocco. Annual data are employed since quarterly data are consistently available only since the early 2000 . We limit attention to this subset of countries for two reasons. First, data considerations prevent us to use a larger sample of non-EU countries - in the sensitivity analysis, we add Croatia, Bosnia, Montenegro, Slovenia, and Lebanon, but we are forced to work with a much shorter time interval. Second, while the UFM partnership relates the whole EU with non-EU Mediterranean countries, we consider only Mediterranean EU members to keep our cross section balanced, as far as developed, emerging and frontier economies are concerned. Focusing on Mediterranean EU may a-priori entail a loss of information, e.g., when examining fluctuations in Turkey or Cyprus, but we expect the biases to be small since most of the historical, cultural and economic links between the EU and the Mediterranean are via Spain, France and Italy.

Business cycle indicators are constructed using real GDP, real consumption and real investment growth, all converted into international standard via PPP adjustments, as it is typical in the literature (see e.g. Kose et. al. 2009). Other private 
sector variables (such as employment) or public sector variables (such as government expenditure or primary balance) are available either irregularly or for a too short sample to make estimation meaningful. Simultaneously including output and consumption in the empirical model is crucial to distinguish different hypotheses put forward in the literature (cyclical convergence of consumption and output fluctuations vs. cyclical consumption convergence and cyclical output divergence). To provide information about the nature of business cycles in smaller and more open economies, the analysis also considers terms of trade (TOT) growth and the trade balance to GDP ratio. They are not directly used in the construction of the cyclical indicators because the starting point of this data is very irregularly distributed over the sample.

The exogenous variables, all entering contemporaneously in the VAR, are the world real GDP and the US federal funds rate, both provided by the WEO. After some experimentation, oil prices were excluded because they are highly correlated with the world real GDP measure. All the variables of the system are demeaned and standardized prior to estimation. This makes the equal weighting scheme in (6)(7) and the analysis coherent. Given the frequency of the data, lag length selection criteria all prefer just one lag in the original panel VAR model.

\subsection{Some features of the Mediterranean economies}

Before proceeding with the analysis, we present some facts about the less known Mediterranean economies. Most of the information comes from the Euromediterranean statistics compiled by Eurostat; it is available at www.eeas.europa.eu/ euromed/index_en.htm, and refers to 2009, if not otherwise noted.

If we exclude Israel, non-Euro area countries in the Mediterranean are poor. Their per-capita income ranges from 2,161 US dollar in Egypt to 10,472 US dollars in Turkey and the poorest countries are all located in the Middle East-North African (MENA) region. In comparison, the income per-capita of Albania (the only non-EU European country in our the database) is almost twice as large as the one of Egypt or Morocco. Poverty ratios reinforce the conclusion: between 20 and 30 percent of the population 
is poor in Morocco, Algeria, and Egypt.

Despite the existence of trade and tariff barriers, the majority of the economies of the Mediterranean region are open. For example, the trade to GDP ratio for the countries in the MENA region is above 80 percent and exceeds 100 percent in Tunisia (data refers here to 2007). Trade by non-EU countries of the region with EU members is about 10 percent of total EU trade and has consistently increased since 2004 at a rate of about 10 percent a year. Similarly, the share of EU trade in non-EU countries has increased, even though at a smaller rate (about 5 percent a year). Thus, North-South trade linkages have intensified over time but not dramatically so. Morocco, Algeria, Turkey and Israel are the countries which trade most with EU members. Trade is primarily concentrated in goods (in particular, fuel, manufacturing and clothing) while trade in services is low - less than 5 percent of total EU trade. Interestingly, bilateral flows among the non-EU countries of the region are low in absolute terms (less than 5 percent of the total) and relative to other regions of the world (e.g. bilateral trade in Asia accounts for roughly 30 percent of total trade). Infrastructural bottlenecks, trade restrictions and, most importantly, non-complementarity of the exports could be responsible for this pattern.

FDIs from the richer to the poorer nations of the Mediterranean have doubled since 2000 but their magnitude is still small: in absolute terms they account for less than one percent of the total FDIs of the EU. Lack of transparency and poor business environment are typically blamed for these low numbers but lack of infrastructures and absence of regional markets are also significant factors. Financial linkages are not quantifiable, but are likely to be limited by legislation restrictions and the riskiness of the region, plagued by civil and religious conflicts. Most the less advanced countries in the regions have financial sectors which are bank-based, with underdeveloped capital markets and this may explain the limited spillover of the global financial turmoil to the region (see Sturm and Sauter (2010) for details).

Migrations from the East to the West of the Mediterranean were strong in the early 1990s but they have been progressively substituted by South to the North migrations. 
Remittances from the EU are important for North African countries, even though migrations flows have been reduced in the last few years, and they account between 12-20 percent of the annual GDP in Morocco and 6-9 percent of annual GDP in Egypt. Thus, remittances, more than trade and FDIs, could be important source of imported fluctuations in portions of the Mediterranean.

Finally, the role of tourism as a source of transmission of cyclical fluctuations needs to be emphasized. The Mediterranean region receives a considerable amount of tourists every year and the flow from the EU has been quite cyclical, reflecting the conditions of the domestic economies. For example, the percentage of tourists entering Tunisia from the EU has suffered a 10 percent decline during the slowdown of 2001 and 2002 relative to the previous years. Also, given that the tourism industry accounts for a large fraction of employment and GDP in many of the poor countries in the region, fluctuations in tourist arrivals and expenditure could be an important source of disturbances in many countries. To give an idea of the importance of the sector, in Tunisia tourism accounts for almost 25 percent of GDP and more than 30 percent of employment and in Egypt around 15 percent of GDP and 18 percent of employment. Even in countries with less developed tourism industry, such as Albania, the sector has grown at a rate of about 15 percent a year in the last 5 years and now accounts for about 10 percent of total GDP.

In sum, trade in goods, remittances and tourism could be important channels through which fluctuations are transmitted across in the region. Cyclical conditions in the EU may be an important factor for domestic fluctuations in each of the nonEU Mediterranean countries, but intra non-EU spillovers are likely to be small. An interesting question is whether remittances and tourism are sufficient to make cyclical fluctuations in countries facing different types of shocks alike. Similarly, one would like to know whether stronger interdependences changed the nature of fluctuations in the area or whether idiosyncratic factors still dominate.

Table A.1 in the appendix presents a few cyclical statistics for the variables used in the investigation. Overall, there appears to be substantial differences in the un- 
conditional moments we report. In addition, differences do not seem to be easily reconciled with the institutional or development indicators used in the literature. In the next sections, we dig deeper into these issues with our panel-VAR model.

\section{The results}

The presentation is organized around four main themes: similarities of cyclical fluctuations; relative importance of exogenous, regional and idiosyncratic factors in explaining the fluctuations; convergence of fluctuations over time; future evolution of business cycles in the area. Each theme is discussed in a separate subsection.

\subsection{Are cyclical fluctuations alike?}

To start with, we examine whether Mediterranean business cycles are similar and, if not, what kind of characteristics matter for grouping fluctuations in the area. To this end, we estimate a number of models, allowing $\theta_{1 t}$, the common factor in the coefficient vector to have one, two, three or four dimensions. To be precise, all models we consider have 16 country-specific, 3 variable-specific factors in the coefficient vector, thus acknowledging the possibility these influences may be present in the data, but differ in the specification of the common factor structure. In the baseline model, the common factor is a scalar; in the alternative models, it has more dimensions. Hence, the baseline model would give a good fit if fluctuations in the basin were similar; the alternatives would be preferable if fluctuations cluster around different poles of attraction. Since there are many ways of assigning the coefficients into groups, we follow Canova (2004) and create groups using observable indicators. Among all combinations we tried, we report in Table 1 a subset which possess two characteristics: groups have some meaningful economic interpretation; the fit of the model - as measured by the marginal likelihood - is good.

The marginal likelihood, which we compute using an harmonic mean estimator, is akin to an $\bar{R}^{2}$, and tells us whether fluctuations in the endogenous variables are 
explained by the model or not. Thus, for a given number of groups, the higher is the marginal likelihood of a particular assignment to groups, the better the fit is. To formally evaluate the goodness of fit across specifications which differ either in the assignment to the groups, given a number of groups, or in the number of groups, one needs a loss function. With a standard 0-1 loss function, differences of 2.2 (4) in the log of the marginal likelihood will make a model significantly (definitively) worse.

The model with one common factor is inferior to all other models and differences are large. Thus, fluctuations in the Mediterranean basin are not alike. However, it is somewhat more difficult to decide how many groups should be allowed for and along which dimension cyclical fluctuations should be clustered around. A common factor with four dimensions is preferable to a common factor with two dimensions, but differences when the common factor has three or four dimensions are small.

Interestingly, taking the number of groups as given, the best fitting models all have nice economic interpretations. For example, the best specification obtained when the common factor has two dimensions is the one that loads one factor on the coefficients of the variables of Euro area countries and the other on the coefficients of the variables of the other countries; in a model with three common factors, the best fitting models are obtained when factors load along income and geographical dimensions. Note that when the common factor has either three or four dimensions, clustering business cycles using trade openness or the level of development produce a lower fit ${ }^{1}$. Thus, economies with similar trade openness or similar level of development do not necessarily have more similar business cycles, and intensifying trade ties, as proposed by the UFM partnership, will not necessarily make Mediterranean cycles more alike.

The best specification clusters business cycles in four clubs: one includes the variables of Portugal, Spain, France, Italy and Greece (which, for ease of exposition, we label the West), one the variables of Cyprus, Albania, Malta, Turkey (labelled the East), one the variables of Syria, Israel and Jordan (labelled the Middle East)

\footnotetext{
${ }^{1}$ One can guess that this occurs because the major trading partners of some countries are outside the Mediterranean and because remittances and tourism overshadow the importance of development indicators.
} 
and one the variables of Egypt, Tunisia, Algeria and Morocco (labelled North Africa). While this is not an exact geographical ordering, geography seems important to determine how cyclical fluctuations behave ${ }^{2}$. Since standard explanations for geographical patterns are hard to entertain - production structures are quite similar in the Mediterranean and institutions are still fragile in many countries - further research, along the lines of Altug et. al. (2011), is needed to explain this finding.

The literature typically conditions on the level of development or similar indicators in examining cyclical fluctuations and, for example, Kose et al. (2009) in their analysis of world business cycles find that the relevant distinction is between developed, developing and emerging markets economies. Others, for example Altug and Bildirici (2010), believe that the global or local nature of shocks matters. Our results are closer in spirit to those of Benczur and Raftai (2010) who, using simple unconditional statistics, find that the preferred grouping of the business cycles of 58 world economies has to do with their historical and geographical characteristics. Our findings are also consistent with those of Canova et al. (2009), who find that changes in monetary arrangements had limited effects on cyclical fluctuations in Europe.

\subsubsection{The dynamic patterns of regional indicators}

To better understand the outcome of our clustering procedure and to highlight in what way regional cycles are different, Figure 1 plots the four regional indicators the best model produces. In each box there are three lines: the black line is the median of the posterior distribution at each point in time; the blue lines represent a pointwise 68 percent posterior credible set. In the first box, together with the West indicator, we also plot in red, the indicator obtained in a model with just one common factor.

The West indicator is relatively persistent, it displays three recessions located at the official CEPR dates for the whole Euro area (represented by the shaded area), two relatively vigorous expansions culminating with peaks in 1988 and 1998, and a

\footnotetext{
${ }^{2}$ When the MENA region is treated as a whole the model has only a marginally lower fit than the best specification while using an exact geographical classification, i.e. moving Greece into the East and Malta into North Africa, considerably reduces the fit (log marginal likelihood $=-1433$ ) .
} 
significant slowdown around 2001-2002. The synchronicity of the cyclical fluctuations in the region changes over time and dispersion is largest around the two cyclical peaks (posterior credible sets are wider at these dates). The current recession is deeper than the two previous ones - both the median value and the credible set are much lower than in other occasions - and somewhat more persistent. Thus, this indicators captures well what is known about business cycles of Southern members of the EU and this should increase our confidence about what the model delivers for the cyclical fluctuations of less studied Mediterranean areas. Note that the West indicator and the common indicator are not perfectly correlated - the latter also captures influences present in the East and in the MENA regions - since the standardization we employ puts fluctuations in small and large economies on the same scale.

The East indicator is much less persistent than the West indicator and has numerous ups and downs. In particular, it displays significant recessions with troughs in $1985,1991,1994,1997,1999,2001,2009$, roughly every 3-4 years, and visible expansions culminating with peaks in 1987, 1995, 2004. The relative frequency of the ups and downs makes the indicator very similar to the one obtained for a selected number of developing economies in e.g. Kose and Prasad (2010). The synchronicity of the cyclical fluctuations in this region also changes over time but dispersion does not necessarily increase around the cyclical peaks. Three other features make the East indicator different from the West indicators: i) expansion and recession phases are, roughly, of similar length; ii) cycles are more symmetric in amplitude, and iii) downturns are more synchronized with US downturns than with EU downturns (the shaded areas here are NBER recession phases) - the fact that Turkey and Cyprus have important links with Anglo-Saxons countries may be the responsible for this fact. Thus, excluding the last three years, business cycles in the East and the West of the Mediterranean are fundamentally different (see table 2 for other statistics).

The Middle East indicator has peculiar features. It displays relatively long recessionary periods (see, e.g. the period from 1982 to 1990); persistent stagnation phases (see, the period from 1995 to 2003), and relatively sharp but short expansions (the 
shaded areas here are NBER recession phases) . The fluctuations of this indicator have low concordance with both EU and US fluctuations, and for example, in the 1990-92 period, when the US and the EU were simultaneously or individually in a recession, the indicator displays a period of sustained expansion. Interestingly, the indicator shows only a mild and temporary decline after 2008, indicating that the countries of this block largely escaped the turmoil affecting developed countries.

The North African indicator displays important negative serial correlation, considerable volatility and two long upward trends starting in 1994 and 2001. The last expansionary episode lasts until the end of the sample but a considerable slowdown occurs after 2008. Thus, over the last two decades, the countries of this block displayed a generic process of growth convergence within the Mediterranean, a process similar to the one experienced by other frontier economies relative to the rest of the world (see Kose and Prasad, 2010). The timing of the cyclical fluctuations in this region is different from the one observed in the EU or the US (shaded areas here are the union of CEPR and NBER official recession dates): the indicator features three recessionary phases, with troughs in 1982, 1986, 1991-93 and four expansion phases culminating in 1983, 1990 and 1998 and 2008. Since some countries in the block are oil and gas exporters, one may conjecture that the persistent increase in oil and natural gas prices has something to do with the long expansion of the 2000s. Such an explanation, however, is not very compelling because not all the countries in the region enjoy these resources; and because oil prices are highly correlated with the world GDP measure we use. Structural reforms, including more open access to internal markets, are more likely to be responsible for the growth convergence pattern experienced by the region.

In sum, our approach clusters Mediterranean cycles around different (regional) poles of attraction because fluctuations in the basin are heterogeneous in terms of amplitude, duration, and concordance. In addition, while the features of regional cycles are evolving, there is little evidence that they are becoming more similar, and geographical proximity with the EU had, at least so far, little influence on the way 
non-EU Mediterranean economies behave over the cycle. The crisis of 2008 altered this pattern, but it is to early to decide whether the stronger comovements experienced after that date herald a permanent change in the nature of Mediterranean fluctuations or are simply the result of a powerful common shock.

\subsection{The drivers of domestic fluctuations}

To highlight what drives cyclical fluctuations in the region and to quantify how integrated the Mediterranean is in the world economy, we report in Table 3, for each country-variable pair, the average fraction of the volatility explained by the predetermined portion of the regional indicators (panel A) and by the exogenous indicator (panel B), calculated as $W L I_{t}^{e x}+C L I_{t}^{e x}$. We also decompose the fluctuations in each variable, for each country, and at each point in time into their components and plot, in figures 2 to 4 , the actual values of the variables and the contributions of the predetermined regional indicators (blue bars) and of the idiosyncratic indicators (red bars), where the latter captures variable plus idiosyncratic factors.

In the West, and excluding Greece, the regional indicator explains a large proportion of output, consumption and investment growth fluctuations on average, but little of the fluctuations in the trade balance to GDP ratio and in TOT growth. The percentage for output is larger than the one reported in e.g. Canova et al. (2007) or Kose and Prasad (2010), because the regional indicator is more homogeneous. Had one used, e.g. all the countries in the EU to build the indicator, these percentages would have been considerably smaller. The proportions vary over time and the relative importance of the regional indicator increases, e.g., in France, Spain, Portugal in 1998 and 2008, and decreases, e.g., in Spain and Greece in the early 2000s. Note also, somewhat surprisingly, that idiosyncratic influences are generally more important for consumption growth than for output or investment growth

In the East, the regional indicator explains little of the fluctuations in real GDP, consumption and investment growth, and has almost no explanatory power for the trade balance to GDP ratio and for TOT growth. Here idiosyncratic factors mat- 
ter quite a lot and dominate, e.g., output fluctuations in Malta, consumption and investment fluctuations in Cyprus, and output and consumption fluctuations in Albania. In Turkey instead regional and idiosyncratic factors equally matter for output, consumption or investment growth fluctuations.

In the Middle East, the average proportion of fluctuations explained by the regional indicator is low. In addition, idiosyncratic factors become more important as time goes by, at least for consumption and investment growth. In North Africa, cyclical fluctuations of output, consumption and investment growth are dominated by a combination of country specific and idiosyncratic influences but their relative importance changes over time. Interestingly, the regional indicator largely drives the growth miracle of the last decade, supporting the idea that common institutional changes may be at the root of the convergence process. The regional indicator explains a slightly larger percentage of the fluctuations in the trade balance to GDP ratio and in TOT growth in this region, but the numbers are still small.

The importance of exogenous factors in explaining fluctuations in output, consumption and investment growth is uniformly low. Thus, world economic conditions affect basic macroeconomic variables only indirectly - via lags of the endogenous variables - rather than directly. Exogenous factors are however more important for fluctuations in TOT growth and in trade balance to GDP ratio.

Taken together these patterns stand in striking contrast with those reported for other parts of the world and go against the predictions of a number of models of the international business cycle. For example, the dichotomy we uncover, with consumption, investment and output growth primarily explained by endogenous factors and TOT growth and trade balance to GDP ratio primarily explained by exogenous factors, imply sectorial segmentations and the presence of different types of shocks driving the dynamics of domestic variables. Moreover, the fact that in many countries idiosyncratic factors are more important for consumption than output growth makes it difficult to rationalize cyclical fluctuations as optimal responses of risk averse agents to output shocks and highlights the role that (underground) remittances may have in 
driving a cyclical wedge between the two variables. Similarly, the fact that, over the cross section, output and consumption fluctuations are not necessarily driven by the same type of disturbances make the evidence hard to reconcile with the idea that TFP differences drive cross-country cyclical differences. Finally, since trade links increased after 1995, but the pre and post 1995 evidence is roughly similar, cast serious doubts about the role of trade in making Mediterranean cycles more interconnected.

\subsection{Convergence or decoupling?}

The question of whether cyclical fluctuations are converging or not has received a lot of attention in the literature, but the conclusion is still controversial. The fact that idiosyncratic sources of fluctuations matter for a number of countries in the region, but their importance is neither systematically increasing nor systematically decreasing, seems inconsistent with both the convergence and the decoupling propositions.

To provide further evidence on the issue, we plot in figure 5, pairwise rolling correlations between the regional indicators. Rolling correlations are computed using 10 years of data ending at the date listed on the horizontal axis. If convergence (decoupling) takes place, we should see these correlations uniformly increase (decrease) with time. The correlations display distinct periods of convergence and decoupling across different regions. For example, the estimated correlation between the West and the East indicators has a U-shaped pattern: the correlations was positive in the 1980s, it dropped to zero in the middle of the 1990s, and dramatically increased after 2008. A similar pattern is visible when considering the West and the Middle East indicators, while the correlation between the West and the North Africa indicators starts negative, becomes positive and high in the 1990s and drops close to zero afterwards. The only correlation which clearly indicates convergence is the one of the East and the Middle East indicators: it starts negative, it becomes positive in the 1990s and reaches a stable maximum afterwards. Thus, cyclical fluctuations in the basin have gone through periods of increased and decreased synchronicity.

Figure 6, which presents the dynamic responses of the East, Middle East and 
North African indicators to a positive shock common to the variables of the West has a similar message. Dynamic effects are computed orthogonalizing the covariance matrix of the reduced form shocks, assuming that the West block comes first - a natural choice given the patterns of trade, remittance and tourism flows previously discussed. The panels report responses computed in 1993, 2002, 2007; black lines represent median estimates; blue lines the 68 percent posterior intervals.

Shocks originating in the West had different effects on the North African indicator over time: responses first become stronger relative to the 1992 and then weaker - an initial process of convergence was aborted later on. Consistently with the rolling correlations evidence, the responses of the East and the Middle East show similar patterns and, relative to 1992, the transmission from the West has equally weakened in the East and the Middle East. Thus, regional interdependences are changing over time, but the changes are temporary and the direction of the changes is region specific. As far as we know, a pattern of this type has not been previously documented and calls into question common explanations for the convergence/decoupling phenomena based on TFP or on structural parameter differences.

\subsection{What is next?}

How persistent are the patterns we have described in the previous subsection? To shed light on future business cycle developments in Mediterranean we conduct a simple forecasting exercise: we use information up to 2010 to estimate the model and forecast assuming that during the prediction sample that no shocks will hit either the variables or the estimated coefficients and that the exogenous variables will take the values forecasted by the WEO. Our empirical model is well suited for this exercise and, as shown in Canova and Ciccarelli, 2009, it has good properties when compared with existing forecasting approaches.

Figure 7 reports, for each country, the value of the real GDP growth up to 2010 and the 90 percent posterior credible forecast interval (the blue dashed lines) for 2011-2015. For comparison, we also plot WEO forecasts for the same horizons (red 
solid line) even though they differ in two important aspects: they include information up to the second quarter of 2011, which is not available in our annual model; they are based on country specific semi-structural models rather than a purely descriptive statistical multi-country model.

Our forecasts are close to those of the WEO and, for many countries, the qualitative features of the predictions coincide. For example, for the countries in the West region, the current stagnation is expected to last long and there is a non-negligible probability that the growth rate of real GDP in 2011-2015 will be below its mean value. Our predictions for the 2011-2012 are slightly rosier for Portugal and significantly worse for Greece but differences with WEO forecasts are eliminated by 2013. In the East bloc, no double-dip recession is expected and in some countries, such as Cyprus and Malta, growth is expected to be vigorous. Differences with WEO forecasts are larger for this region and, for example, our forecasts are more bullish for Malta and Cyprus and more bearish for Turkey, at least for 2012. Thus, difficulties for East Mediterranean countries were transitory and real GDP is expected to revert to (above) normal growth rate in the future.

The forecasts for the Middle East region are generally less upbeat than those of the WEO and our model predicts that the growth rate of real GDP for these countries will revert to the average national level experienced over the past decade. Finally, the forecast for the North Africa countries are mixed but the long positive differential expansion these countries experienced in the last decade is likely to end. Clearly, since our model conditions on the information available at the end of 2010, it misses the drop in GDP growth due to the popular uprising of the first part of 2011. On the other hand, the sustained growth pattern predicted by the WEO for Egypt and Tunisia in 2014-2015 rests on the assumption that structural reforms will achieve their goals, a scenario which is unquantifiable in our model.

To summarize, if the existing conditions continue unchanged into the future, the West will suffer longer than the East, and the path of GDP growth in Western countries is expected to be below its national average for quite a while. In addition, 
the extraordinary expansion phase experienced by the North Africa region is likely to terminate. All in all, global convergence of GDP fluctuations is unlikely to take place in the basin in the years to come. But perhaps more importantly, even regional convergence seems difficult to achieve. In each of the boxes of figure 7 we report, in green, the average growth rate of the region. In many instances, the green line is outside the posterior 90 percent credible set in the forecasting sample, indicating that the national segmentation of fluctuations will not disappear in the near future.

\section{Some robustness analysis}

Data of countries other than the 16 we consider are consistently available only since the late 1990's. What would happen to our conclusions if a larger cross section (but a shorter time series) is used to select the specification of the model and to construct indicators? Would the tendencies we have described change? Would heterogeneity become stronger or weaker? To answer these questions we add Croatia, Bosnia Montenegro, Slovenia, Lebanon to our sample of countries but use data from 2000 in the estimation. The shorter time series makes median estimates less reliable, but the presence of a sufficiently large cross section keeps standard errors reasonable and estimation results interpretable.

We examined the fit of various model specifications and confirmed that clustering along a geographical dimension is preferable to clustering along the trade or the development dimension. Once again, the fit of a model with three geographical indicators is close to the one with four indicators, but the latter remains the best. The optimal grouping is now strictly less geographical but location is still a strong attractor to group cycles. In fact, the West indicator still captures fluctuations which are common to France, Italy, Spain, Portugal and Greece; the Balcan-East indicator now captures fluctuations common to Cyprus, Malta, Albania, Croatia, Montenegro, Slovenia and Bosnia; the Middle East indicator captures cycles common to Turkey, Israel, Jordan, Syria and Lebanon. Finally, the North Africa indicator captures cycles common to 
Egypt, Morocco, Algeria and Tunisia.

Figure 8 plots the time path of the indicators the extended model delivers. For comparison, we superimposed in red the point estimate of the indicator obtained with the sample of 16 countries. While there are understandable numerical differences, the pattern of the two indicators over the common sample is very similar. There is a significant downturn in Mediterranean EU in 2008 and a similar significant downturn

in the Balcan- East region at the same date; the Middle East indicator shows a sustained growth period in the mid-2000s and a mild recession since 2008; the North Africa indicator displays sustained growth-convergence in the 2000s, partially interrupted in 2009. Thus, the heterogeneities we found are robust. In addition, the optimal groupings we obtain confirm that being part of the Euro is not crucial to understand the nature of cyclical fluctuations in the basin.

\section{Conclusions}

This paper investigates the features of cyclical fluctuations in 16 Mediterranean countries, studies the relative importance of exogenous, regional and idiosyncratic factors in determining the magnitude of the fluctuations, examines the nature of the convergence process and forecasts future tendencies in the area. The analysis is conducted with a dynamics statistical model which allows for country specific dynamics, cross country lagged interdependencies and time variations, and permits the construction of observable indicators capturing a number of interesting influences.

The analysis uncovers three major facts. First, Mediterranean cycles are quite heterogeneous but heterogeneities are not associated with the typical development or trade indicators, emphasized in the literature. Instead, there seems to be a geographical component in the fluctuations, not directly linked with difference in production structures or monetary institutions. Idiosyncratic influences matter quite a lot for some countries in the basin, and although not uniformly, they affect consumption more than output growth. Thus, business cycles in the Mediterranean are not alike; 
their structure differs from the one observed in, say, East Asia or South America; their evolution does not conform to the general international trends; and integration efforts have done little to change their segmented structure.

Second, while there are changes in the way EU cyclical fluctuations are transmitted to the countries in the area, these changes are not easily reconciled with either a pure convergence or a pure decoupling view of cyclical fluctuations. Both phenomena seem to be present in Mediterranean, but more importantly, both appear to be local and temporary. Thus, also in this aspect, the Mediterranean differs from the broad international trends described, e.g., in Kose and Prasad, 2010.

Third, if the current state persists, global cyclical convergence is unlikely to occur and even regional convergence will be difficult to obtain. There will be readjustments in the years to come, with Mediterranean EU countries suffering for quite a long time and countries in the east quickly returning to above average growth rates. However, GDP cycles are not expected to become more similar in the years to come.

The policy implications of our findings are numerous. For example, the presence of important heterogeneities and their persistence over time, despite the recent integration efforts by the EU, casts doubts about the effectiveness of the UFM partnership, at least in the current format. Many countries in the Mediterranean live out of tourism revenues and remittances. Thus fostering mobility more than intensifying trade or financial ties may help to make business cycles more alike in the area. The fact that idiosyncratic features matter and that their relative weight is expected to be unchanged in the near future is also important. Whether this is a good or a bad news for policy depends on whether one has in mind some regional insurance mechanism (idiosyncrasies are good) or a currency area mechanism (idiosyncrasies are bad). No matter which view is taken, the process of integration and shared prosperity, envisioned by the UFM partnership, still has a long way to go.

Our analysis also has important implications for theoretical models of the international business cycles. For example, the fact that cross-country differences in business cycle fluctuations do not appear to be related with natural resources, pro- 
duction structures, financial market frictions or differences in the productivity process cast doubts on existing theories explaining international differences in business cycles. Moreover, the fact that cycles in the major macroeconomic variables are driven by idiosyncratic forces in a number of countries is also a major setback for current models of the business cycle where consumption smoothing in the face of fluctuating income is a priority for risk averse agents. To understand the nature of cyclical fluctuations in the area current models need to be modified in many directions - for example, they need to be highly disaggregated and have important national specificities - and the role of tourism and remittances should be explicitly taken into account. 


\section{References}

[1] Aguiar, M. and Gopinath, G., 2008. Emerging markets business cycles. The trend is the cycle, Journal of Political Economy, 115, 69-102.

[2] Altug, S. and Bildirici, M., 2010, A Markov switching approach to business cycles around the globe, Koc University, manuscript.

[3] Benczur, P. and Raftai, A., 2010. Business cycles around the globe, Central European University, manuscript.

[4] Canova, F., 1993. Modelling and Forecasting Exchange Rates with a Time varying coefficient Bayesian Model, Journal of Economic Dynamics and Control, 17, 233-261.

[5] Canova, F., 2004. Testing for convergence club in income per-capita: a predictive density approach, International Economic Review, 45, 49-77.

[6] Canova, F., and Ciccarelli, M., 2009. Estimating multi-country VAR models. International Economic Review, 50, 929-961.

[7] Canova, F., Ciccarelli, M., and Ortega, E., 2007. Similarities and convergence in G-7 cycles, Journal of Monetary Economics, 54, 850-878.

[8] Canova, F., Ciccarelli, M., and Ortega, E., 2009 Do institutional changes affect business cycles? ECB working paper.

[9] Chang, R., and Fernandez, A., 2010. On the sources of aggregate fluctuations in emerging economies, Rutgers University, manuscript.

[10] Chib, S., and Greenberg, E., 1995. Hierarchical analysis of SUR models with extensions to correlated serial errors and time-varying parameter models. Journal of Econometrics, 68, 409-431.

[11] Del Negro, M. and Schorfheide, F., forthcoming. Bayesian Macroeconometrics. in J. Geweke, G. Koop, and H. Van Dijk (eds.) Handbook of Bayesian Econometrics, Oxford University Press.

[12] Geweke, J., 2000. Simulation based Bayesian inference for economic time series in Mariano, R., Schuermann, T. and Weeks, M. (eds.). Simulation based inference in 
econometrics: methods and applications, Cambridge, UK: Cambridge University Press.

[13] Garcia-Cicco, J., Pancrazi, R., and Uribe, M., 2010, Real business cycles in emerging countries, American Economic Review, 100, 2510-2531.

[14] Helbling, T., and Bayoumi, T., 2003. Are they all in the same boat? The 20002001 growth slowdown and the G-7 business cycle linkages. IMF working paper, $1-42$.

[15] Kose, A., Otrok, C., and Prasad, E., 2009. Global business cycles: convergence or decoupling?, forthcoming, International Economic Review.

[16] Kose, A., and Prasad, E., 2010 Emerging markets. Resilience and growth amid global turmoil. Brookings Institution Press, Washington, DC.

[17] Kadiyala, K.R., and Karlsson, S., 1997. Numerical methods for estimation and inference in Bayesian-VAR models. Journal of Applied Econometrics 12, 99-132.

[18] Kydland, F., and Zarazaga, C., 2002. Argentina lost decade, Review of Economic Dynamics, 5, 152-165.

[19] Heathcothe, J., and Perri, F., 2004. Financial globalization and real regionalization, Journal of Economic Theory, 119, 207-243.

[20] Sturm, M. and N. Sauter, 2010. The impact of the global financial turmoil and recession on Mediterranean countries' economies, ECB Occasional Paper no. 118.

[21] Walti, S., 2009. The myth of decoupling, Swiss National Bank manuscript. 
Table 1: Log Marginal Likelihoods

\begin{tabular}{|c|c|c|c|c|c||}
\hline \hline Model & One common & Two common & $\begin{array}{c}\text { Three common } \\
\text { Development }\end{array}$ & $\begin{array}{c}\text { Three common } \\
\text { Income }\end{array}$ & $\begin{array}{c}\text { Three common } \\
\text { Trade }\end{array}$ \\
\hline Log ML & -1440 & -1433 & -1433 & -1431 & -1438 \\
\hline Model & $\begin{array}{c}\text { Three common } \\
\text { Geography }\end{array}$ & $\begin{array}{c}\text { Four common } \\
\text { Trade }\end{array}$ & $\begin{array}{c}\text { Four common } \\
\text { Geography }\end{array}$ & $\begin{array}{c}\text { Four common } \\
\text { Income }\end{array}$ & $\begin{array}{c}\text { Four common } \\
\text { Development }\end{array}$ \\
\hline Log ML & -1430 & -1431 & -1429 & -1430 & -1431 \\
\hline
\end{tabular}

In the model with two common factors, one loads on the variables of countries adopting the Euro and one for the others. The model with three common factors clusters countries according to the level of development (low, medium, high); the level of income (low, medium, high); trade openness (low, medium, high); and the location (West, East and MENA). The model with four common factors slices countries according to trade (low, medium, high, extreme); level of development (very low, below average, above average, high); the level of income (very low, below average, above average, high); and according to location (West, East, Middle East and North Africa). The best model with four common indicators has one indicator loading on the coefficients of the variables of Portugal, Spain, France, Italy and Greece, one on the coefficients of the variables of Malta, Cyprus, Albania, and Turkey; one for the coefficients of the variables of Israel, Syria and Jordan; the last on the coefficients of the variables of Egypt, Tunisia, Algeria and Morocco.

Table 2: Basic statistics

\begin{tabular}{|l|c|c|c|c||}
\hline \hline Indicator & West & East & Middle East & North Africa \\
\hline Standard deviation & 0.12 & 0.09 & 0.18 & 0.20 \\
\hline AR $(1)$ & 0.66 & 0.03 & 0.23 & 0.31 \\
\hline Contemporaneous correlation with West & & 0.42 & -0.06 & 0.01 \\
\hline
\end{tabular}

The indicators are computed with the best model found in table 1 . 
Table 3.A: Percentage of the variance explained by the regional indicators

\begin{tabular}{|l|c|c|c|c|c|c||}
\hline \hline & & $\begin{array}{c}\text { Output } \\
\text { growth }\end{array}$ & $\begin{array}{c}\text { Investment } \\
\text { growth }\end{array}$ & $\begin{array}{c}\text { Consumption } \\
\text { growth }\end{array}$ & $\begin{array}{c}\text { Trade balance } \\
\text { over GDP }\end{array}$ & $\begin{array}{c}\text { TOT } \\
\text { growth }\end{array}$ \\
\hline West & France & 0.83 & 0.82 & 0.56 & 0.12 & 0.15 \\
& Italy & 0.64 & 0.73 & 0.68 & 0.01 & 0.02 \\
& Spain & 0.93 & 0.90 & 0.89 & 0.03 & 0.01 \\
& Portugal & 0.65 & 0.58 & 0.49 & 0.01 & 0.10 \\
& Greece & 0.31 & 0.33 & 0.35 & 0.01 & 0.01 \\
\hline East & Cyprus & 0.42 & 0.17 & 0.17 & 0.01 & 0.18 \\
& Malta & 0.23 & 0.37 & 0.18 & 0.06 & 0.01 \\
& Turkey & 0.44 & 0.31 & 0.28 & 0.03 & 0.07 \\
& Albania & 0.05 & 0.04 & 0.15 & 0.02 & 0.05 \\
\hline Middle & Israel & 0.41 & 0.39 & 0.27 & 0.01 & 0.06 \\
East & Jordan & 0.44 & 0.35 & 0.45 & 0.03 & 0.01 \\
& Syria & 0.57 & 0.08 & 0.31 & 0.01 & 0.03 \\
\hline North & Egypt & 0.23 & 0.27 & 0.04 & 0.01 & 0.13 \\
Africa & Morocco & 0.13 & 0.41 & 0.06 & 0.13 & 0.09 \\
& Algeria & 0.43 & 0.57 & 0.35 & 0.22 & 0.10 \\
& Tunisia & 0.12 & 0.28 & 0.24 & 0.01 & 0.14 \\
\hline \hline
\end{tabular}

Table 3.B: Percentage of the variance explained by exogenous factors

\begin{tabular}{|l|c|c|c|c|c|c||}
\hline \hline & & $\begin{array}{c}\text { Output } \\
\text { growth }\end{array}$ & $\begin{array}{c}\text { nvestment } \\
\text { growth }\end{array}$ & $\begin{array}{c}\text { Consumption } \\
\text { growth }\end{array}$ & $\begin{array}{c}\text { Trade balance } \\
\text { over GDP }\end{array}$ & $\begin{array}{c}\text { TOT } \\
\text { growth }\end{array}$ \\
\hline West & France & 0.04 & 0.01 & 0.07 & 0.05 & 0.15 \\
& Italy & 0.11 & 0.03 & 0.15 & 0.21 & 0.38 \\
& Spain & 0.02 & 0.01 & 0.02 & 0.14 & 0.33 \\
& Portugal & 0.06 & 0.07 & 0.18 & 0.25 & 0.29 \\
& Greece & 0.14 & 0.28 & 0.15 & 0.22 & 0.28 \\
\hline East & Cyprus & 0.04 & 0.07 & 0.06 & 0.05 & 0.16 \\
& Malta & 0.03 & 0.01 & 0.01 & 0.04 & 0.38 \\
& Turkey & 0.01 & 0.01 & 0.01 & 0.05 & 0.16 \\
& Albania & 0.02 & 0.06 & 0.08 & 0.37 & 0.40 \\
\hline Middle & Israel & 0.17 & 0.01 & 0.15 & 0.11 & 0.21 \\
East & Jordan & 0.01 & 0.02 & 0.14 & 0.03 & 0.15 \\
& Syria & 0.09 & 0.22 & 0.04 & 0.09 & 0.21 \\
\hline North & Egypt & 0.05 & 0.06 & 0.02 & 0.29 & 0.04 \\
Africa & Morocco & 0.01 & 0.01 & 0.01 & 0.18 & 0.12 \\
& Algeria & 0.01 & 0.03 & 0.03 & 0.18 & 0.04 \\
& Tunisia & 0.13 & 0.13 & 0.07 & 0.24 & 0.14 \\
\hline \hline
\end{tabular}




\section{Figure 1. Regional Indicators}

Posterior median (black), 68\% Bayesian credible interval (blue), and median common indicator (red)
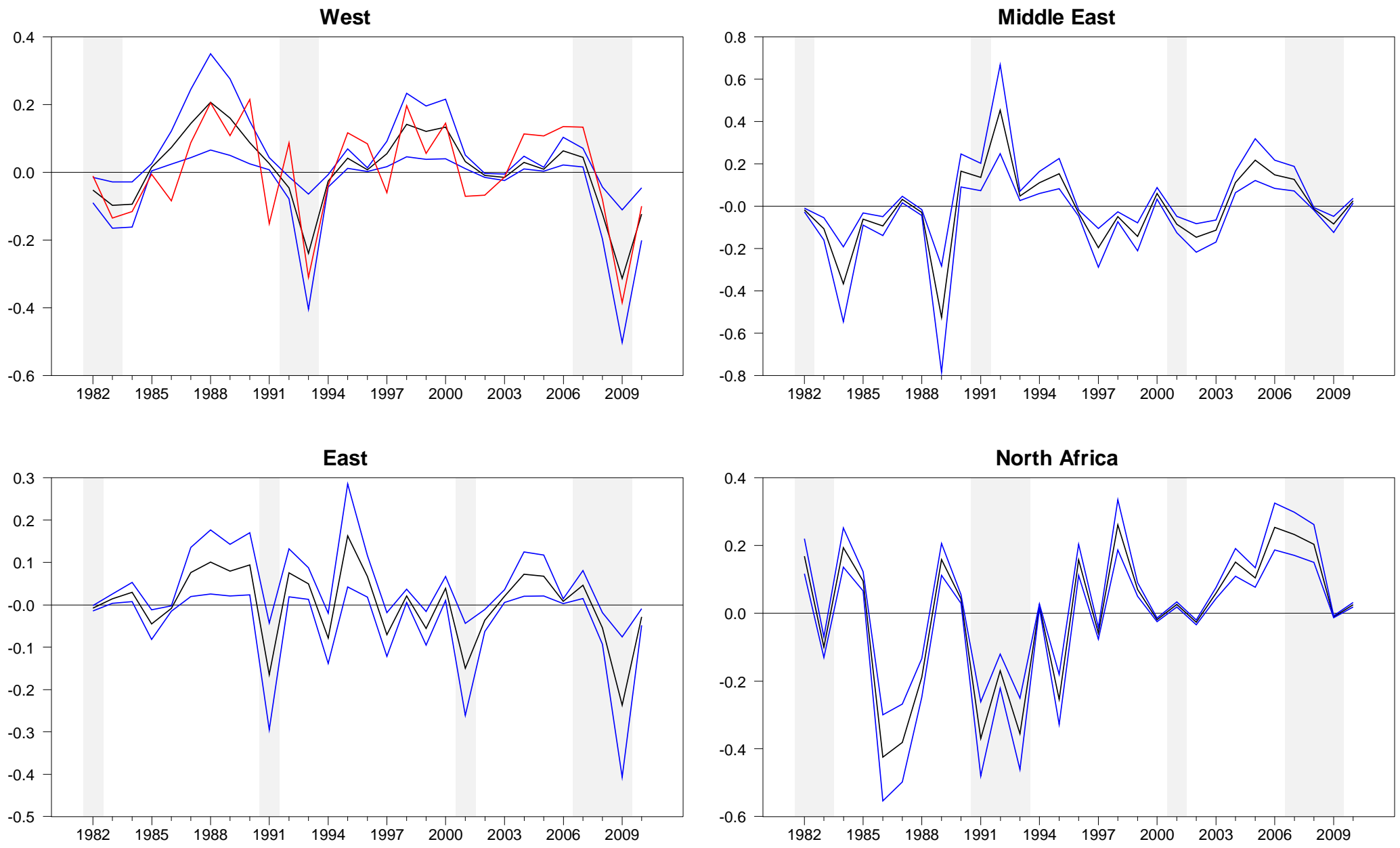
Figure 2. Historical decomposition

West

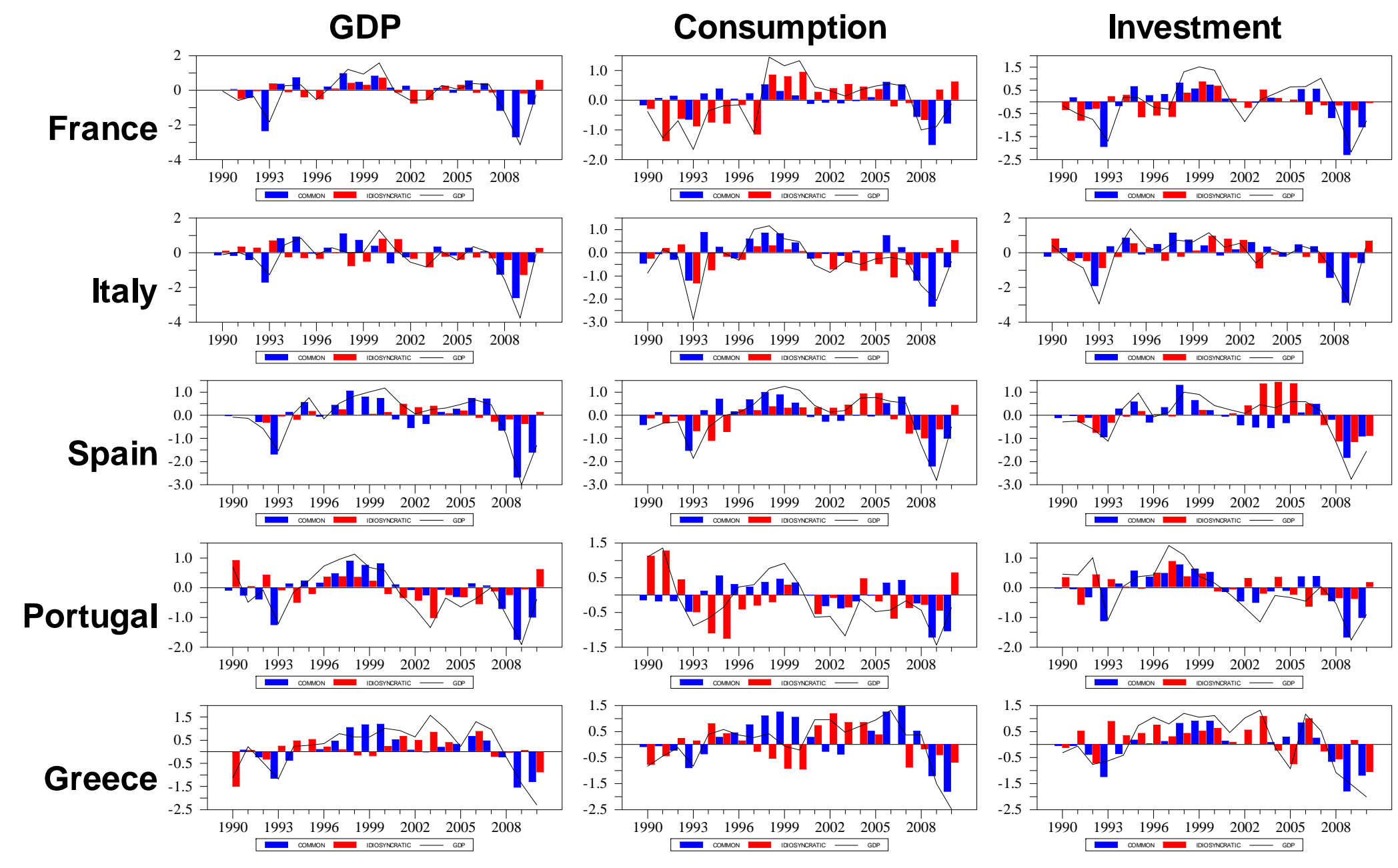


Figure 3. Historical decomposition

East
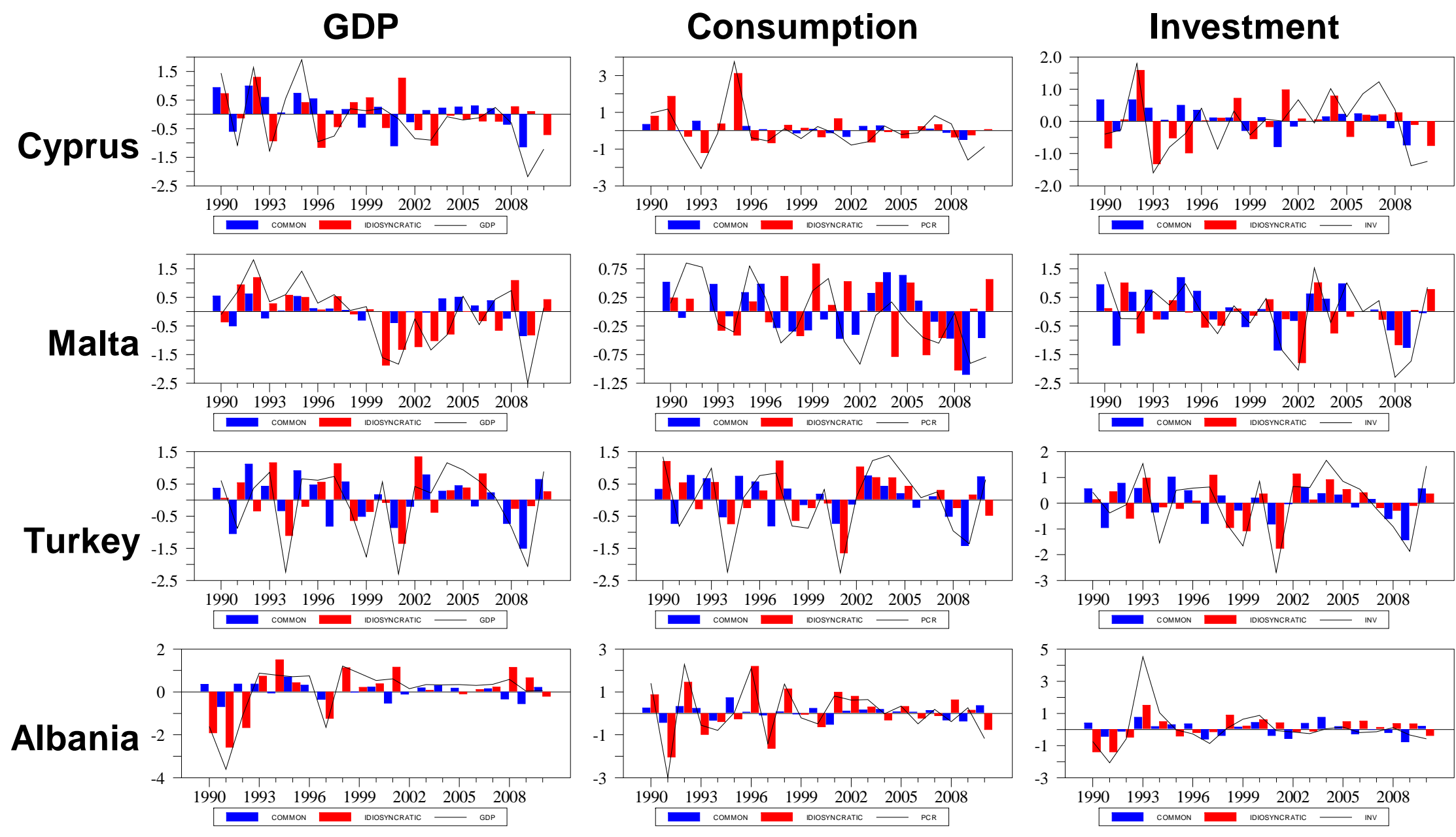
Figure 4. Historical decomposition Middle East and North Africa

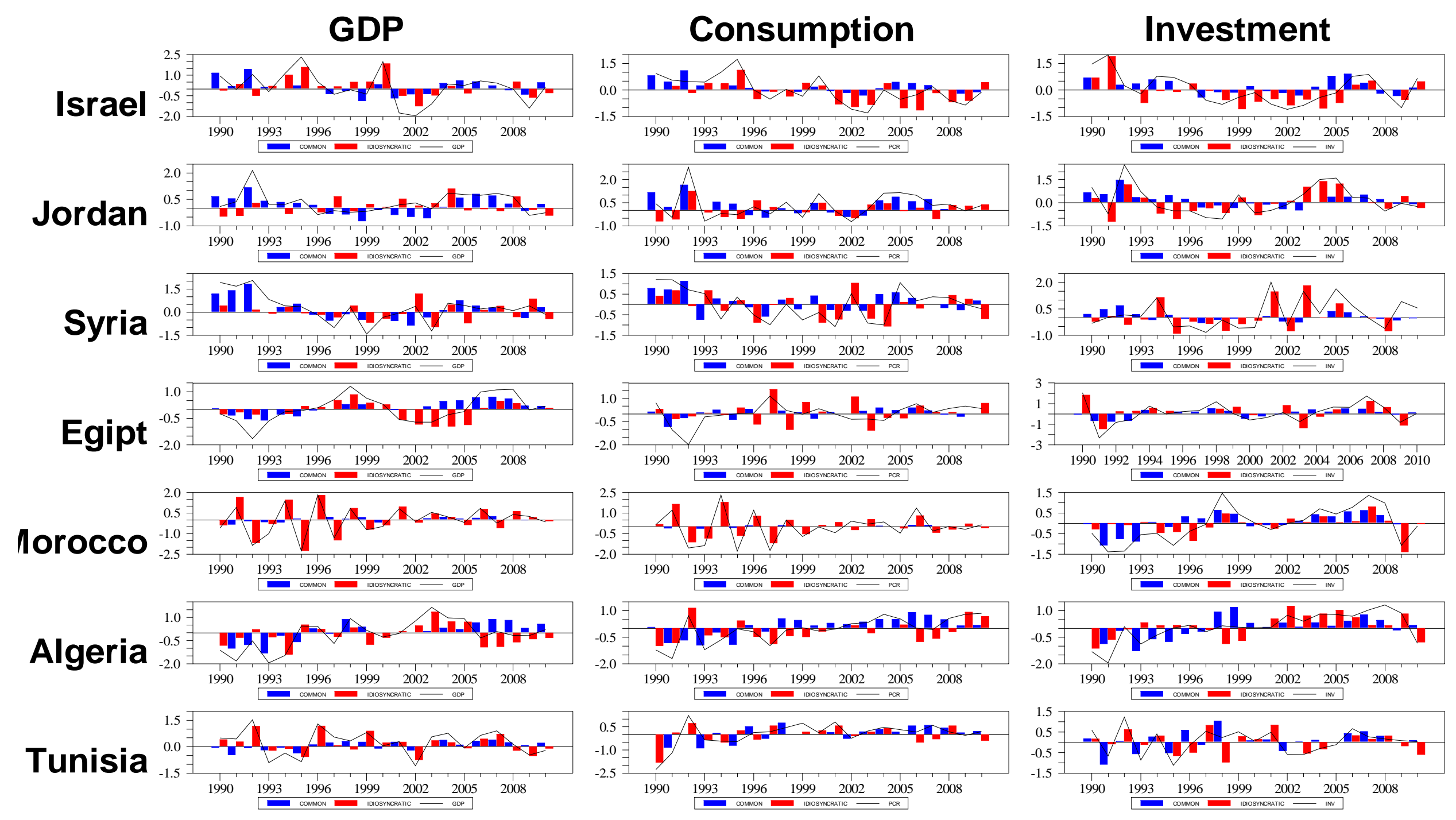


Figure 5. Pairwise rolling correlations

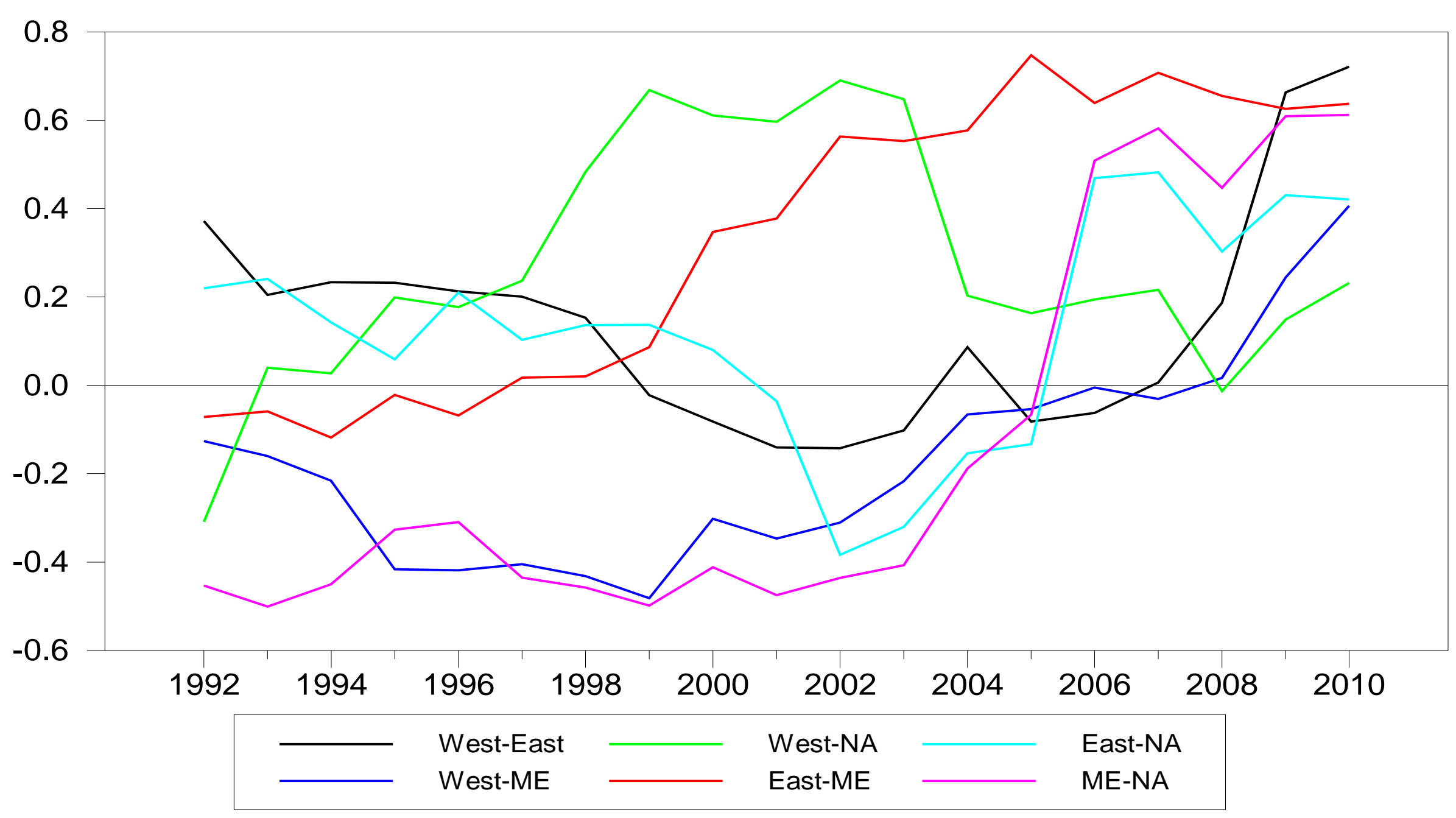


Figure 6. Generalised impulse responses. Shock to West variables

Posterior median and 68\% Bayesian credible interval

Responses of the EAST indicator

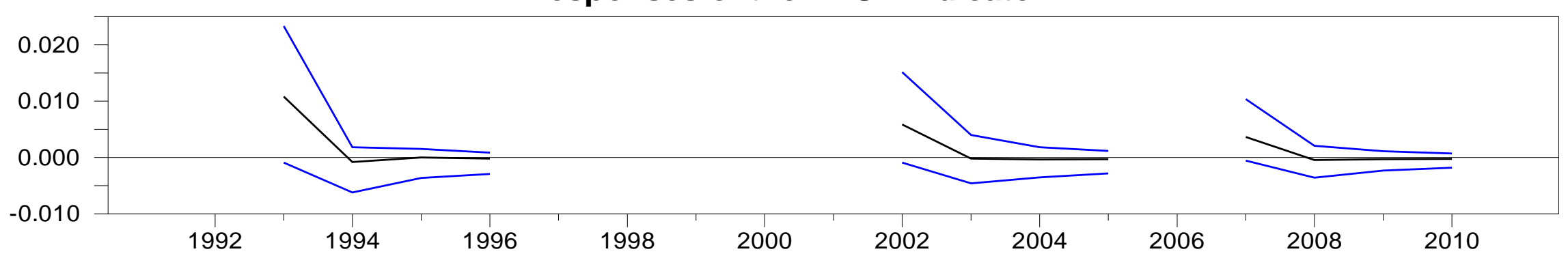

Responses of the Middle East indicator

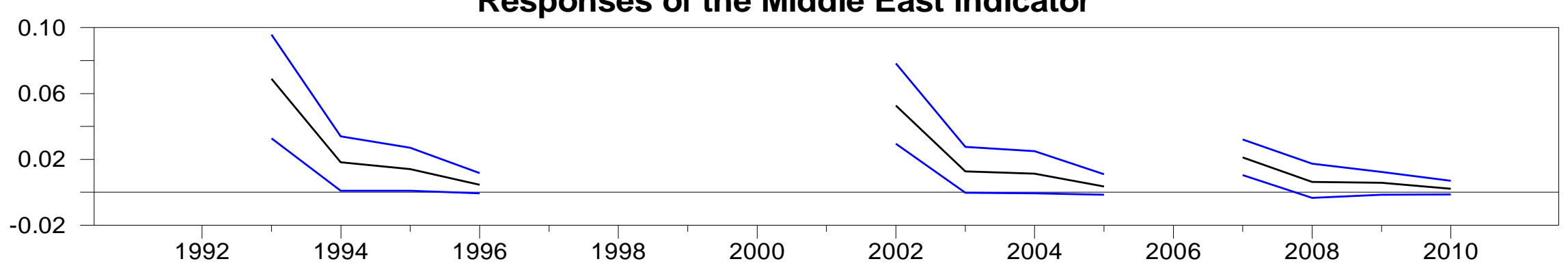

Responses of the North Africa indicator

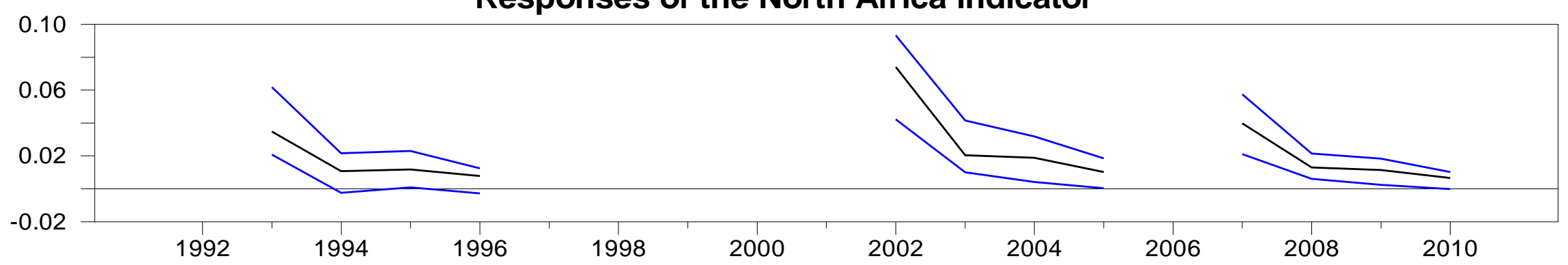


Figure 7. Forecasting GDP growth: Comparing with the WEO

WEO (red), 68\% Bayesian credible interval (blue), and regional mean (green)
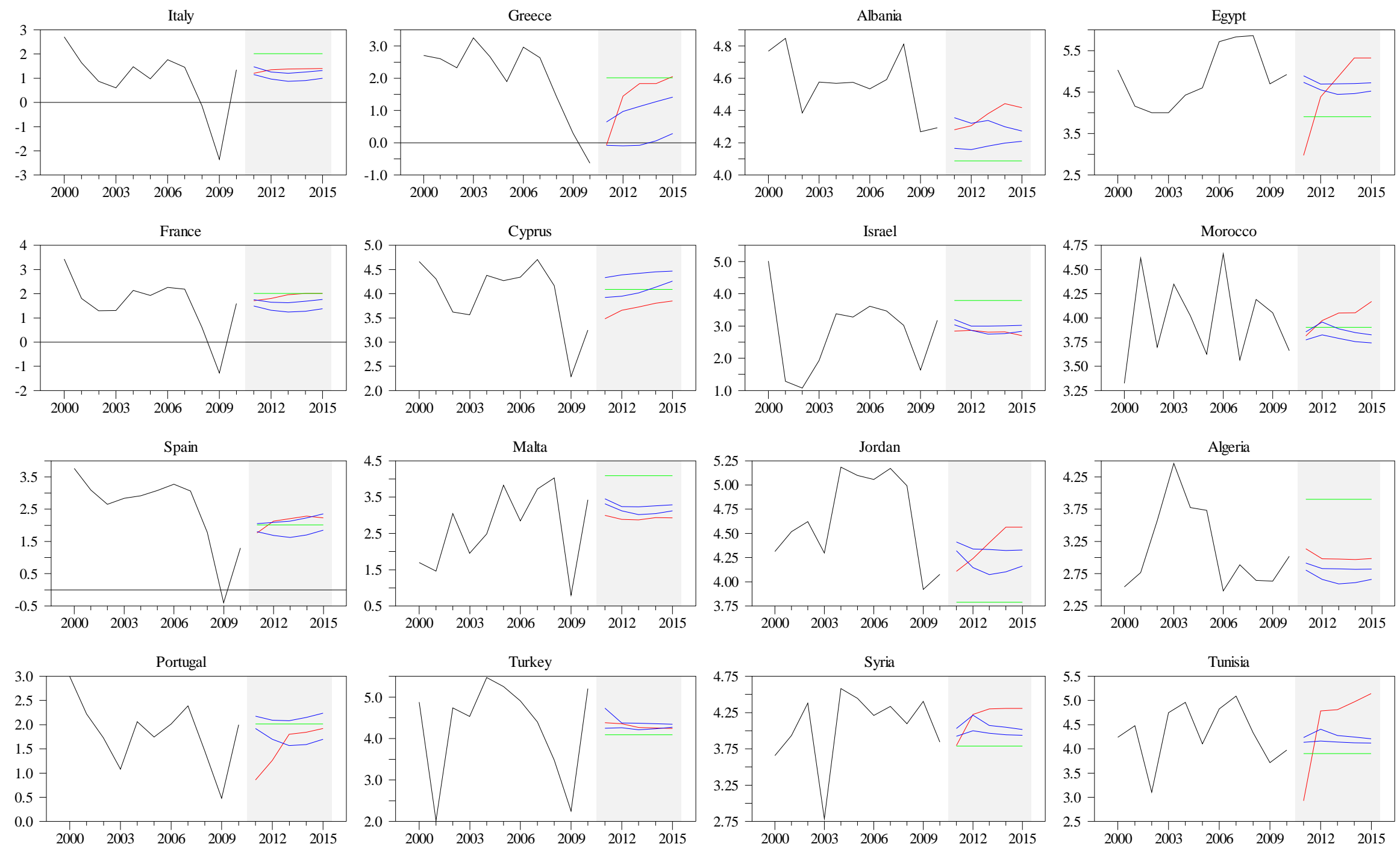


\section{Figure 8. Regional Indicators. Extended model}

Posterior median (black), 68\% Bayesian credible interval (blue), and median indicator of original model (red)
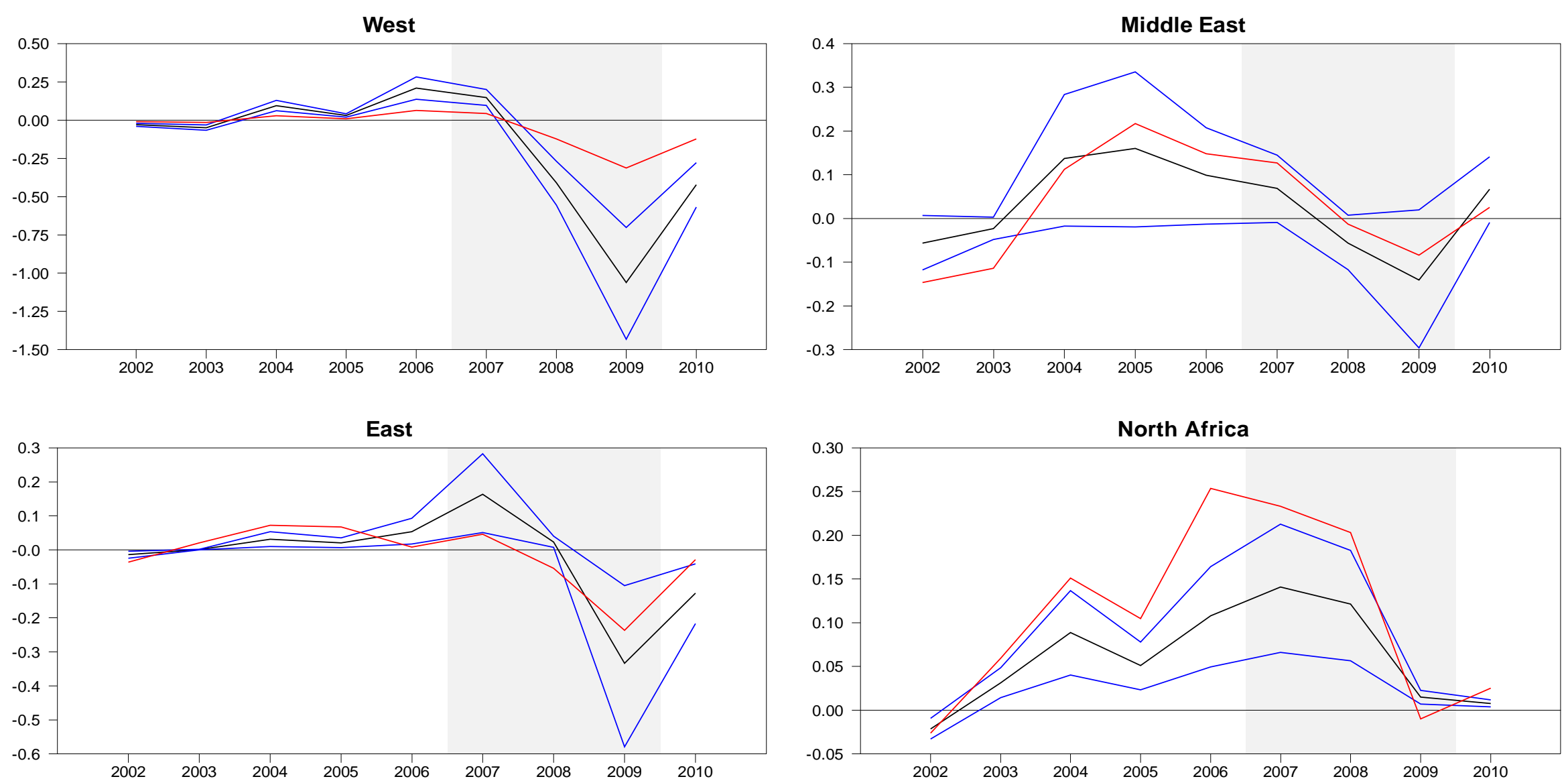
TABLE A1. Stylized facts

\begin{tabular}{|c|c|c|c|c|c|c|c|c|c|c|c|c|c|c|c|c|c|c|c|c|}
\hline & \multicolumn{5}{|c|}{ FRANCE } & \multicolumn{5}{|c|}{ ITALY } & \multicolumn{5}{|c|}{ SPAIN } & \multicolumn{5}{|c|}{ PORTUGAL } \\
\hline & pcr & inv & gdp & trade & ToT & pcr & inv & gdp & trade & ToT & pcr & inv & gdp & trade & Тот & pcr & inv & gdp & trade & ToT \\
\hline std dev & 1.39 & 4.10 & 1.41 & 0.01 & 2.47 & 1.66 & 4.36 & 1.76 & 0.02 & 5.36 & 2.36 & 6.93 & 2.11 & 0.02 & 4.78 & 2.74 & 7.96 & 2.54 & 0.03 & 6.01 \\
\hline AR(1) & 0.79 & 0.69 & 0.82 & 0.96 & 0.03 & 0.74 & 0.41 & 0.67 & 0.77 & 0.00 & 0.83 & 0.75 & 0.88 & 0.97 & 0.38 & 0.82 & 0.53 & 0.79 & 0.96 & -0.20 \\
\hline \multirow[t]{3}{*}{$\max$ corr } & 0.72 & 0.86 & 0.85 & 0.68 & 0.85 & 0.69 & 0.75 & 0.85 & 0.68 & 0.76 & 0.72 & 0.86 & 0.85 & 0.70 & 0.85 & 0.63 & 0.62 & 0.68 & 0.57 & 0.71 \\
\hline & \multicolumn{5}{|c|}{ GREECE } & \multicolumn{5}{|c|}{ CYPRUS } & \multicolumn{5}{|c|}{ MALTA } & \multicolumn{5}{|c|}{ TURKEY } \\
\hline & pcr & inv & gdp & trade & ToT & pcr & inv & gdp & trade & ToT & pcr & inv & gdp & trade & ToT & pcr & inv & gdp & trade & ToT \\
\hline $\min$ corr & -0.35 & -0.32 & -0.14 & -0.54 & -0.36 & -0.24 & -0.26 & -0.23 & -0.25 & -0.16 & -0.42 & -0.34 & -0.39 & -0.53 & -0.10 & -0.26 & -0.27 & -0.33 & -0.68 & -0.56 \\
\hline \multirow[t]{3}{*}{$\max$ corr } & 0.57 & 0.63 & 0.61 & 0.70 & 0.45 & 0.45 & 0.41 & 0.63 & 0.44 & 0.50 & 0.45 & 0.39 & 0.53 & 0.65 & 0.12 & 0.18 & 0.39 & 0.38 & 0.77 & 0.23 \\
\hline & \multicolumn{5}{|c|}{ ALBANIA } & \multicolumn{5}{|c|}{ ISRAEL } & \multicolumn{5}{|c|}{ SYRIA } & \multicolumn{5}{|c|}{ JORDAN } \\
\hline & pcr & inv & gdp & trade & ToT & pcr & inv & gdp & trade & ToT & pcr & inv & gdp & trade & Тот & pcr & inv & gdp & trade & ToT \\
\hline std dev & 8.09 & 47.25 & 8.02 & 0.13 & 23.58 & 4.33 & 10.91 & 2.47 & 0.04 & 3.26 & 8.75 & 17.03 & 4.93 & 0.09 & 14.43 & 9.45 & 12.18 & 4.98 & 0.07 & 19.09 \\
\hline max corr & pcr & inv & gdp & trade & ToT & pcr & inv & gdp & trade & ToT & pcr & inv & gdp & trade & Тот & pcr & inv & gdp & trade & ToT \\
\hline std dev & 3.96 & 16.27 & 2.13 & 0.03 & 8.77 & 5.17 & 6.81 & 4.60 & 0.06 & 6.71 & 3.83 & 7.27 & 2.48 & 0.09 & 20.40 & 2.34 & 9.43 & 2.30 & 0.02 & 3.76 \\
\hline AR(1) & 0.40 & 0.04 & 0.97 & 0.98 & -0.53 & -0.02 & 0.52 & 0.15 & 1.02 & -0.34 & 0.57 & 0.46 & 0.78 & 0.92 & 0.07 & 0.74 & 0.39 & 0.77 & 0.97 & 0.13 \\
\hline $\min$ corr & -0.35 & -0.03 & -0.34 & -0.16 & -0.26 & -0.35 & -0.20 & -0.33 & -0.76 & -0.26 & -0.65 & -0.50 & -0.39 & -0.70 & -0.65 & -0.43 & -0.27 & -0.21 & -0.36 & -0.44 \\
\hline max corr & 0.33 & 0.55 & 0.36 & 0.44 & 0.63 & 0.26 & 0.55 & 0.27 & 0.77 & 0.50 & 0.55 & 0.44 & 0.36 & 0.50 & 0.24 & 0.55 & 0.46 & 0.26 & 0.43 & 0.45 \\
\hline
\end{tabular}

